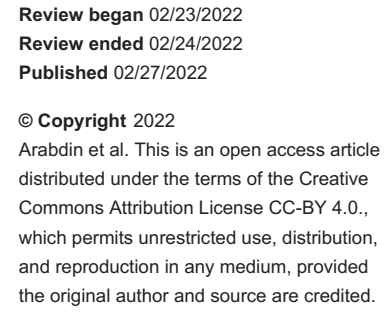

\section{Frequency and Severity of Thrombocytopenia in Neonatal Sepsis}

\author{
Maria Arabdin ${ }^{1}$, Adnan Khan ${ }^{2}$, Sikandar Zia ${ }^{1}$, Sarbiland Khan ${ }^{3}$, Gulrukh S. Khan ${ }^{4}$, Maryam Shahid ${ }^{5}$ \\ 1. Department of Pathology, Rehman Medical College, Peshawar, PAK 2. Department of Pediatrics, Rehman Medical \\ Institute, Peshawar, PAK 3. Clinical Haematology, Kingston Hospital NHS Foundation Trust, London, GBR 4. \\ Department of Medicine, Rehman Medical Institute, Peshawar, PAK 5. Department of Physiology, Khyber Medical \\ College, Peshawar, PAK
}

Corresponding author: Adnan Khan, adnan.khan-10@rmi.edu.pk

\section{Abstract \\ Background}

Neonatal sepsis includes numerous systemic illnesses such as septicemia, meningitis, urinary tract infections, and pneumonia. In developing countries, the major reason for neonatal mortality is septicemia, which accounts for almost $50 \%$ of overall deaths. Thrombocytopenia is one of the most common hematological problems during the neonatal period, affecting the majority of sufferers admitted to the neonatal intensive care unit (NICU). The aim of our study was to find the frequency of thrombocytopenia and its severity in neonates with sepsis.

\section{Methods}

The study was conducted at the Department of Hematology at Khyber Medical University, Peshawar, Pakistan. A total of 170 neonates with an age of fewer than 28 days, both genders, and positive blood cultures were included in the study using a non-probability consecutive sampling technique. Data was recorded in predesigned questionnaires after taking informed consent. Data were recorded and analyzed using SPSS version 26 (IBM Corporation, Armonk, NY, USA).

\section{Results}

Of the 170 neonates, 104 (61.2\%) were males, with a mean age of $12.12 \pm 8.88$ days. The majority of the babies 73 (42.9\%) were in the age group of 0-7 days. Most of the neonates 72 (42.4\%) were born via normal vaginal delivery (NVD). Of the neonates, 117 (68.82\%) presented with fever, and 105 (61.76\%) were reluctant to feed. Furthermore, $65.29 \%$ of the neonates had thrombocytopenia, of which 34 (20\%) had mild, 43 (25.3\%) had moderate, and 34 (20\%) had severe thrombocytopenia. In neonates with positive blood culture, the platelet level was low ( $\mathrm{p}<0.001)$. In the case of gram-negative organisms, the level of platelets was lower as compared to gram-positive organisms $(\mathrm{p}<0.001)$.

\section{Conclusion}

Sepsis is still a common cause of newborn thrombocytopenia. The fact that it is present in more than half of all culture-positive sepsis episodes indicates the severity of the condition. This condition is further defined by higher percentages of early-onset gram-negative septicemia compared to gram-positive sepsis.

Categories: Pediatrics, Infectious Disease, Hematology

Keywords: critical care, neonatal intensive, thrombocytopenia, sepsis, neonates

\section{Introduction}

Neonatal sepsis incorporates diverse systemic ailments such as septicemia, meningitis, urinary tract infections, and pneumonia [1]. In developing international locations, the primary cause of neonatal death is septicemia, accounting for almost $50 \%$ of general deaths [2,3]. Its miles assessed that sepsis develops in $20 \%$ of neonates, of which $1 \%$ die in the early days [4]. The reported incidence for sepsis ranges from 1 to 10 per 1000 live births, but studies based on a huge population are rare, and the available data mostly is aimed at infants with high risk such as premature or very low birth weight (VLBW) infants in developed countries [5]. Based on the onset, sepsis is divided into three categories: early-onset sepsis (fewer than three days of age), late-onset sepsis (LOS) (at 3-28 days of age), and late late-onset sepsis (at 29-120 days of age). Among all three types, late-onset sepsis (LOS) is frequent, particularly in VLBW neonates. One of the early indicators for neonatal sepsis is thrombocytopenia [6].

Thrombocytopenia is one of the most common hematological disorders at newborn age, affecting the majority of neonates admitted to the NICU [7]. Neonates admitted to NICUs develop thrombocytopenia in $20 \%-35 \%$ of all admissions, and a hike in percentage is noted with a drop in gestational age $[8,9]$. The 
majority of neonates present with mild to moderate thrombocytopenia. Sepsis in the newborn is one of the chief causes of thrombocytopenia in neonates, and it can become very severe and can increase the risk of bleeding within 24 hours after developing an infection [10].

The exact mechanism of low platelets in neonatal sepsis is unknown, but it has been proposed that sepsis causes endothelial injury, which in turn triggers the reticuloendothelial system. Platelet consumption exceeds production and causes thrombocytopenia [11]. Thrombocytopenia and neonatal sepsis associations have been highlighted by recognizing thrombocytopenia as the prominent key risk feature for sepsis-related fatalities in neonates [12].

An observational study by Noreen et al. showed that the frequency of thrombocytopenia is higher in neonates admitted to the NICU for any reason [13]. Neonatal sepsis must not be considered as a homogenous entity, as it spurns both the pathogenic and clinical variations among numerous causative microorganisms and clinical syndromes and features of septicemia. No local study has been done in the recent past that emphasizes the incidence of thrombocytopenia in neonatal sepsis. In this research, we will present the characteristics of thrombocytopenia related to sepsis in both gram-negative and gram-positive cells. This will be beneficial for early diagnosis and treatment, predicting morbidity and mortality. The results of this study will provide us with local statistics on the magnitude of neonatal thrombocytopenia in sepsis, and this will provide a window for further research.

\section{Materials And Methods}

This was a descriptive cross-sectional study conducted at the Department of Hematology at Khyber Medical University, Peshawar, Pakistan. The sample size was calculated according to the WHO formula by taking the prevalence of thrombocytopenia in neonates as $20 \%$ [12], a margin of error of $6 \%$, and a confidence interval of $95 \%$. A non-probability consecutive sampling technique was adopted. All neonates less than 28 days old, of both genders, and positive blood culture were included. Those with a mother's history of ITP, SLE, or other autoimmune disorders on medication during pregnancy (sulfonamides, quinine, quinidine, thiazides, tolbutamide, vancomycin, hydralazine, and heparin) and neonates with a history of bleeding disorders in the family, trisomies, or Turner/Noonan's syndromes were excluded.

The study was to commence after approval was obtained from the Advanced Studies and Research Board and ethical board of Khyber Medical University, Peshawar, Pakistan. The aim of our investigation was explained to all parents/guardians, and informed written consent was taken as well. Patient information such as demographics and clinical examinations was recorded on a purposefully designed questionnaire. Blood samples were collected from each patient by a trained nurse, and the samples were sent to the laboratory for full blood count estimation. The platelet count was less than $150 \times 109 / \mathrm{L}$. A peripheral smear was made, and platelet count and morphology were checked manually. Erythrocyte sedimentation rate (ESR) was also estimated manually. C-reactive protein (CRP) was analyzed from plasma via Cobas 601 (Roche, Basel, Switzerland) and was expressed in $\mathrm{mg} / \mathrm{dL}$.

SPSS version 26 (IBM Corporation, Armonk, NY, USA) was used to record and analyze data. Descriptive statistics were used to calculate the mean and standard deviation of all numerical variables, such as age, hemoglobin level, white blood cell count, platelet count, CRP level, and ESR, while categorical variables (gender, blood culture, age group, mode of delivery, presenting symptoms, and blood group) were presented in percentage and frequency. For the comparative analysis of sociodemographic data, hematological parameters, infective markers, and blood culture, with the severity of thrombocytopenia, ANOVA was used. A p-value of 0.05 was kept as significant.

\section{Results}

The demographic characteristics of the neonates are given in Table 1 . Of the 170 neonates, 104 (61.2\%) were males and 66 (38.8\%) were females. The majority of the neonates $(73,42.9 \%)$ were in the age group of $0-7$ days. The overall mean age of the neonates was $12.12 \pm 8.88$ days; the mean age for males was $11.18 \pm 7.790$ days, while for females, it was $13.62 \pm 10.13$ days. The majority of the neonates $81(47.6 \%)$ were in the weight group between 2.5 and $3.5 \mathrm{~kg}$. Most of the neonates 72 (42.4\%) were born via normal vaginal delivery (NVD). 


\section{Cureus}

\begin{tabular}{|c|c|c|}
\hline Variable & Frequency & Percentage (\%) \\
\hline \multicolumn{3}{|l|}{ Gender } \\
\hline Male & 104 & 61.2 \\
\hline Female & 66 & 38.8 \\
\hline \multicolumn{3}{|l|}{ Age group } \\
\hline $0-7$ days & 73 & 42.9 \\
\hline 8-14 days & 31 & 18.2 \\
\hline 15-21 days & 29 & 17.1 \\
\hline $22-28$ days & 37 & 21.8 \\
\hline \multicolumn{3}{|l|}{ Weight } \\
\hline $2.5-3.5 \mathrm{~kg}$ & 81 & 47.6 \\
\hline $3.6-4.5 \mathrm{~kg}$ & 76 & 44.7 \\
\hline$>4.5 \mathrm{~kg}$ & 13 & 7.6 \\
\hline \multicolumn{3}{|l|}{ Mode of delivery } \\
\hline Normal vaginal delivery & 72 & 42.4 \\
\hline Cesarean section & 49 & 28.8 \\
\hline NVD with episiotomy & 49 & 28.8 \\
\hline \multicolumn{3}{|l|}{ Feeding } \\
\hline Mother breastfeed & 112 & 65.9 \\
\hline Formula milk & 27 & 15.9 \\
\hline Both/mix & 31 & 18.2 \\
\hline
\end{tabular}

TABLE 1: Demographic characteristics of the neonates admitted to the NICU ( $n=170)$

The majority of the mothers experienced no infection during pregnancy. However, only 58 experienced some sort of infection, of which 29 (17.1\%) experienced a flu-like illness, 22 (12.9\%) acute gastroenteritis, and seven (4.1\%) other infections, including chest infection and genital infection. Table 2 shows the hematological and infective markers of the neonates.

\begin{tabular}{|c|c|c|c|c|c|c|c|}
\hline Parameters & $\begin{array}{l}\text { Hemoglobin } \\
\text { (g/dL) }\end{array}$ & $\begin{array}{l}\text { White blood cell } \\
\left(10^{9} / \mathrm{L}\right)\end{array}$ & $\begin{array}{l}\text { Platelet count } \\
\text { (cells/L) }\end{array}$ & $\begin{array}{l}\text { Neutrophils } \\
\text { (\%) }\end{array}$ & $\begin{array}{l}\text { Lymphocytes } \\
\text { (\%) }\end{array}$ & $\begin{array}{l}\text { CRP } \\
\text { (mg/dL) }\end{array}$ & $\begin{array}{l}\text { ESR } \\
\text { (mm/hour) }\end{array}$ \\
\hline Mean & 13.114 & 10.701 & 182.947 & 43.251 & 41.821 & 4.588 & 21.076 \\
\hline $\begin{array}{l}\text { Standard } \\
\text { deviation }\end{array}$ & 2.094 & 15.636 & 156.894 & 10.998 & 10.461 & 7.062 & 14.168 \\
\hline Minimum & 7.80 & 4.39 & 2 & 13.50 & 8.20 & 0 & 9 \\
\hline Maximum & 21.21 & 21.70 & 589 & 78.10 & 81 & 45 & 98 \\
\hline
\end{tabular}

TABLE 2: Mean hematological and infective markers of the neonates admitted to the NICU $(n=170)$ CRP: C-reactive protein, ESR: erythrocyte sedimentation rate

Blood culture was positive in 114 (61\%) of the participants and was negative in 56 (39\%). Furthermore, in positive blood culture, the organisms isolated were gram-negative in 77 (67.54\%) and gram-positive in 27 


\section{Cureus}

(23.68\%). In this study, of the 170 total neonates, 111 (65.29\%) had thrombocytopenia, of which 34 (20\%) had mild (platelets: $101-150$ cells/L), 43 (25.3\%) had moderate (platelets: 50-100 cells/L), and 34 (20\%) had severe thrombocytopenia (platelets: $>50$ cells/L) (Table 3).

\begin{tabular}{|c|c|c|}
\hline Thrombocytopenia & Frequency & Percent (\%) \\
\hline Mild (101-150 cells/L) & 34 & 20 \\
\hline Moderate $(50-100$ cells/L) & 43 & 25.3 \\
\hline Severe $(<50$ cells $/ L)$ & 34 & 20 \\
\hline Normal & 59 & 34.7 \\
\hline
\end{tabular}

TABLE 3: Distribution of thrombocytopenia in the neonates admitted to the NICU $(n=111)$

While comparing blood culture results with thrombocytopenia, it was observed that out of 111, 92 (82.88\%) had positive blood cultures, in which 26 (23.42\%) had mild thrombocytopenia, 34 (30.63\%) had moderate thrombocytopenia, and 32 (28.82\%) had severe thrombocytopenia.

In gram-positive cases, three (3.26\%) had mild thrombocytopenia, 12 (13.04\%) had moderate thrombocytopenia, four (4.34\%) had severe thrombocytopenia, and in gram-negative cases, 23 (25\%) had mild thrombocytopenia, 22 (23.91\%) had moderate thrombocytopenia, and 28 (30.43\%) had severe thrombocytopenia.

By doing comparative analysis by applying ANOVA, it was noted that the age group was statistically significant, with a p-value of 0.010 , which is less than 0.05 . The lower the age group, the lower the platelet level. However, the other parameters were not significant $(\mathrm{p}>0.05)$ : gender, $\mathrm{p}=0.548$; weight, $\mathrm{p}=0.346$; mode of delivery, $\mathrm{p}=0.160$; maternal risk factors, $\mathrm{p}=0.756$; fetal risk factors, $\mathrm{p}=0.096$; and feeding, $\mathrm{p}=0.65$ (Table 4).

\begin{tabular}{|c|c|c|c|c|c|}
\hline Sociodemographic factors & Sum of squares & df & Mean square & $\mathbf{F}$ & Sig \\
\hline Age & 885.559 & 3 & 295.186 & 3.931 & 0.010 \\
\hline Gender & 0.510 & 3 & 0.170 & 0.708 & 0.548 \\
\hline Weight & 1.941 & 3 & 0.647 & 1.112 & 0.346 \\
\hline Mode of delivery & 3.601 & 3 & 1.200 & 1.744 & 0.160 \\
\hline Maternal risk factor & 3.511 & 3 & 1.170 & 0.396 & 0.756 \\
\hline Fetal risk factor & 13.361 & 3 & 4.454 & 2.153 & 0.096 \\
\hline Feeding & 1.005 & 3 & 0.335 & 0.538 & 0.657 \\
\hline
\end{tabular}

TABLE 4: Comparative analysis of the sociodemographic data with the severity of thrombocytopenia $(n=111)$

df: degree of freedom, F: variation, Sig: significance

Similarly, by doing the comparative analysis of hematological, infective, and blood cultures, it was found that it was significant in the case of C-reactive protein; the higher the CRP level, the lower the platelet level, with a p-value of 0.001 . Similarly, in the case of blood culture, it was noted that, with positive blood culture, the platelet level was lower $(\mathrm{p}<0.001)$. Regarding the isolate, it was noted that, in the case of gram-negative organisms, the level of platelets was lower as compared to gram-positive organisms $(\mathrm{p}<0.001)($ Table 5$)$. 


\section{Cureus}

\begin{tabular}{|c|c|c|c|c|c|}
\hline Hematological parameters, infective markers, and blood culture & Sum of squares & df & Mean square & $\mathbf{F}$ & Sig \\
\hline Hemoglobin & 24.218 & 3 & 8.073 & 1.868 & 0.137 \\
\hline White blood cells & 711.604 & 3 & 237.201 & 0.970 & 0.409 \\
\hline Neutrophils & 268.515 & 3 & 89.505 & 0.736 & 0.532 \\
\hline Lymphocytes & 213.628 & 3 & 71.209 & 0.647 & 0.586 \\
\hline C-reactive protein & 1835.711 & 3 & 611.904 & 15.402 & 0.000 \\
\hline Erythrocyte sedimentation rate & 1271.044 & 3 & 423.681 & 2.154 & 0.095 \\
\hline Blood culture & 15.701 & 3 & 5.234 & 35.208 & 0.000 \\
\hline Organism isolated & 17.895 & 3 & 5.965 & 14.967 & 0.000 \\
\hline
\end{tabular}

TABLE 5: Comparative analysis of hematological parameters, infective markers, and blood culture with the severity of thrombocytopenia $(n=111)$

df: degree of freedom, F: variation, Sig: significance

\section{Discussion}

Thrombocytopenia is a common complication of neonatal sepsis and is one of the most prognostic independent causes of sepsis-related death. Every year, over 1.6 million newborn deaths occur worldwide, with $40 \%$ of them occurring in poorer nations, primarily Asia and Africa. This condition is a prevalent concern in neonates with confirmed sepsis, with thrombocytopenia happening in $66 \%$ of the total cases in our cross-sectional study. The results of our study are in good correlation with a cohort study, where $20 \%$ had severe onset of the disease, and the results revealed an almost fourfold increase in mortality in neonatal sepsis with thrombocytopenia [12]. Earlier, Charoo et al. investigated 200 VLBW infants with sepsis, and thrombocytopenia was detected in $61.5 \%$ of them [14]. The increased incidence of thrombocytopenia in VLBW newborns may be due to a partial response to thrombocytopenia in terms of platelet and thrombopoietin production, mostly during sepsis with diminished energy reserves in the host [15].

The use of vascular catheters is strongly linked to intravascular thrombosis. Catheters can enhance platelet consumption [16]. They ultimately lead to vascular wall damage mechanically by altering the flow of blood, but they can also contain possibly thrombogenic agents or be used to inject toxic chemicals into the vascular walls [17]. In our study, males were more affected. This is in accordance with the study of Fanaroff et al., who found that the incidence of sepsis is considerably higher in male newborns than in female ones [18].

The severity of thrombocytopenia differs depending on the causative bacteria. In this study, gram-negative sepsis had a considerably higher rate of early thrombocytopenia than gram-positive sepsis. In 30.43\% of gram-negative sepsis episodes, there was severe early thrombocytopenia, while in gram-positive sepsis, only 4.34\% were investigated for severe thrombocytopenia. This finding supports a prior study that found that thrombocytopenia was more common in gram-negative sepsis [19]. The likely mechanisms of thrombocytopenia associated with gram-negative sepsis are augmented destruction of platelets by absorption, antibody-mediated binding, and activation. In animal models, cell-free extracts comprising lipopolysaccharide and a constituent of gram-negative bacteria's cell wall have been demonstrated to cause thrombocytopenia [20].

According to our findings, blood culture and the degree of thrombocytopenia differ significantly in grampositive versus gram-negative sepsis. Because the mainstream of our study sample had a positive blood culture, we assumed that this was due to the underlying distribution of bacteria. Previous research on the relationship between the kind of gram stain and the prevalence of thrombocytopenia in newborn sepsis has produced mixed results. When relating infections with gram-positive and gram-negative bacteria in neonates with extremely low birth weight, Manzoni et al. found no variance in the occurrence of thrombocytopenia, but they employed a different thrombocytopenia threshold [21]. Others, on the other hand, have observed similar results to ours and claim that thrombocytopenia is more common in gramnegative sepsis [22,23]. However, the size of the sample was typically limited, and outcomes were derived generally from populations of neonates with low birth weight and premature infants. Our findings are based on a large, recent sample of sepsis-affected infants from a variety of gestational ages. Because gramnegative sepsis is more severe than gram-positive sepsis and because sepsis can cause dispersed intravascular clotting, thrombocytopenia may simply be a sign of the severity of sepsis. In neonatal sepsis, an undeviating pathophysiological mechanism of endotoxins formed by gram-negative bacteria could play a role. Both bacterial groupings have a lot of inhomogeneity, with each bacterial species having varying 
degrees of pathogenicity [24].

In our findings, when sociodemographic data were compared with the severity of thrombocytopenia, only the age group was found to be statistically significant. Similarly, while comparing hematological, infectious, and blood complete counts, it was discovered that in the case of C-reactive protein, the greater the CRP level, the lower the platelet level. This finding was also supported by Rabindran et al., in which they studied the CRP with platelet level in neonates and found out that the greater the CRP, the higher the thrombocytopenia [25]. Furthermore, the severity of gram-negative sepsis increased.

Thrombocytopenia should be considered as the first sign of sepsis, even before the rise of infective markers such as CRP and raised TLC in neonates. If a neonate presents with clinical signs and symptoms of sepsis with thrombocytopenia, management should be started even if infective markers are within the normal range.

\section{Conclusions}

In our study, we found that in neonatal sepsis, more than half of the neonates developed thrombocytopenia and $20 \%$ developed severe thrombocytopenia. It was independently associated with gram-negative sepsis, low gestational age, and high CRP. To conclude, it is critical to screen for and treat thrombocytopenia in all babies brought to the NICU, including those who appear to be at low risk, because the incidence and mortality linked with this illness are significant. Because sepsis is still a common cause of newborn thrombocytopenia and the severity of thrombocytopenia in sepsis varies from mild to moderate to severe, the fact that thrombocytopenia is present in more than half of sepsis cases with positive blood cultures indicates the severity of the condition.

\section{Additional Information \\ Disclosures}

Human subjects: Consent was obtained or waived by all participants in this study. Khyber Medical University, Peshawar, Pakistan, issued approval DIR/KMU-AS\&RB/FS/001239. Animal subjects: All authors have confirmed that this study did not involve animal subjects or tissue. Conflicts of interest: In compliance with the ICMJE uniform disclosure form, all authors declare the following: Payment/services info: All authors have declared that no financial support was received from any organization for the submitted work. Financial relationships: All authors have declared that they have no financial relationships at present or within the previous three years with any organizations that might have an interest in the submitted work. Other relationships: All authors have declared that there are no other relationships or activities that could appear to have influenced the submitted work.

\section{References}

1. Aggarwal R, Sarkar N, Deorari AK, Paul VK: Sepsis in the newborn. Indian J Pediatr. 2001, 68:1143-7. 10.1007/BF02722932

2. Memon J, Holakouie-Naieni K, Majdzadeh R, Yekaninejad MS, Garmaroudi G, Raza O, Nematollahi S: Knowledge, attitude, and practice among mothers about newborn care in Sindh, Pakistan . BMC Pregnancy Childbirth. 2019, 19:329. 10.1186/s12884-019-2479-0

3. Bang AT, Bang RA, Baitule SB, Reddy MH, Deshmukh MD: Effect of home-based neonatal care and management of sepsis on neonatal mortality: field trial in rural India. Lancet. 1999, 354:1955-61. 10.1016/S0140-6736(99)03046-9

4. Stoll BJ: The global impact of neonatal infection . Clin Perinatol. 1997, 24:1-21. 10.1016/S00955108(18)30181-7

5. Cailes B, Kortsalioudaki C, Buttery J, et al.: Epidemiology of UK neonatal infections: the neonIN infection surveillance network. Arch Dis Child Fetal Neonatal Ed. 2018, 103:F547-53. 10.1136/archdischild-2017313203

6. Sindhura YS, Reddy KR: A study of neonatal thrombocytopenia in neonatal sepsis . Int J Contemp Med Res. 2017, 4:2250-2.

7. Stanworth SJ, Clarke P, Watts T, et al.: Prospective, observational study of outcomes in neonates with severe thrombocytopenia. Pediatrics. 2009, 124:e826-34. 10.1542/peds.2009-0332

8. Christensen RD, Henry E, Wiedmeier SE, et al.: Thrombocytopenia among extremely low birth weight neonates: data from a multihospital healthcare system. J Perinatol. 2006, 26:348-53. 10.1038/sj.jp.7211509

9. Murray NA, Roberts IA: Circulating megakaryocytes and their progenitors in early thrombocytopenia in preterm neonates. Pediatr Res. 1996, 40:112-9. 10.1203/00006450-199607000-00020

10. Murray NA, Howarth LJ, McCloy MP, Letsky EA, Roberts IA: Platelet transfusion in the management of severe thrombocytopenia in neonatal intensive care unit patients. Transfus Med. 2002, 12:35-41. 10.1046/j.1365-3148.2002.00343.x

11. Brown RE, Rimsza LM, Pastos K, et al.: Effects of sepsis on neonatal thrombopoiesis. Pediatr Res. 2008, 64:399-404. 10.1203/PDR.0b013e318181ad49

12. Ree IM, Fustolo-Gunnink SF, Bekker V, Fijnvandraat KJ, Steggerda SJ, Lopriore E: Thrombocytopenia in neonatal sepsis: incidence, severity and risk factors. PLoS One. 2017, 12:e185581. 10.1371/journal.pone.0185581

13. Noreen N, Amanat S, Ali SJ: Thrombocytopenia in neonatal intensive care unit and role of platelet transfusion. J Rawalpindi Med. 2019, 23:68-71. 
14. Charoo BA, Iqbal JI, Iqbal Q, Mushtaq S, Bhat AW, Nawaz I: Nosocomial sepsis-induced late onset thrombocytopenia in a neonatal tertiary care unit: a prospective study. Hematol Oncol Stem Cell Ther. 2009, 2:349-53. 10.1016/s1658-3876(09)50024-6

15. Sheu JR, Hung WC, Wu CH, et al.: Reduction in lipopolysaccharide-induced thrombocytopenia by triflavin in a rat model of septicemia. Circulation. 1999, 99:3056-62. 10.1161/01.cir.99.23.3056

16. Roberts I, Stanworth S, Murray NA: Thrombocytopenia in the neonate. Blood Rev. 2008, 22:173-86. 10.1016/j.blre.2008.03.004

17. Gunnink SF, Vlug R, Fijnvandraat K, van der Bom JG, Stanworth SJ, Lopriore E: Neonatal thrombocytopenia: etiology, management and outcome. Expert Rev Hematol. 2014, 7:387-95. 10.1586/17474086.2014.902301

18. Fanaroff AA, Korones SB, Wright LL, et al.: Incidence, presenting features, risk factors and significance of late onset septicemia in very low birth weight infants. The National Institute of Child Health and Human Development Neonatal Research Network. Pediatr Infect Dis J. 1998, 17:593-8. 10.1097/00006454199807000-00004

19. Guida JD, Kunig AM, Leef KH, McKenzie SE, Paul DA: Platelet count and sepsis in very low birth weight neonates: is there an organism-specific response?. Pediatrics. 2003, 111:1411-5. 10.1542/peds.111.6.1411

20. Sola MC, Calhoun DA, Hutson AD, Christensen RD: Plasma thrombopoietin concentrations in thrombocytopenic and non-thrombocytopenic patients in a neonatal intensive care unit. Br J Haematol. 1999, 104:90-2. 10.1046/j.1365-2141.1999.01154.x

21. Manzoni P, Mostert M, Galletto P, Gastaldo L, Gallo E, Agriesti G, Farina D: Is thrombocytopenia suggestive of organism-specific response in neonatal sepsis?. Pediatr Int. 2009, 51:206-10. 10.1111/j.1442200X.2008.02689.x

22. Akarsu S, Taskin E, Kilic M, Ozdiller S, Gurgoze MK, Yilmaz E, Aygun AD: The effects of different infectious organisms on platelet counts and platelet indices in neonates with sepsis: is there an organism-specific response?. J Trop Pediatr. 2005, 51:388-91. 10.1093/tropej/fmi031

23. Bolat F, Kılıç SÇ, Oflaz MB, et al.: The prevalence and outcomes of thrombocytopenia in a neonatal intensive care unit: a three-year report. Pediatr Hematol Oncol. 2012, 29:710-20. 10.3109/08880018.2012.725454

24. Yeaman MR: Platelets in defense against bacterial pathogens . Cell Mol Life Sci. 2010, 67:525-44. 10.1007/s00018-009-0210-4

25. Rabindran R, Parakh H, JK R, Reddy P: Comparative study of platelet count and C-reactive protein among gram positive, gram negative and fungal sepsis in newborns. Int J Med Res Rev. 2015, 3:149-56. 10.17511/ijmrr.2015.i2.026 